\title{
PROMOTION OF FIELD PEA PISUM ARVENSE SEEDS GERMINATION WITH BIOLOGICAL PREPARATIONS OF DOMESTIC PRODUCTION
}

\author{
O. V. Vyshnevska, O. V. Markina \\ Institute of Agriculture of Polissya NAAS \\ 131, Kyivse shosse, 10007, Zhytomyr, Ukraine \\ E-mail: oksanavish@rambler.ru
}

The paper covers the research results of biological inoculation effect on field pea Pisum arvense seeds germination under different temperature regimes. The optimum temperatures ensuring high seeds germination rates were defined. It was established that Rhizohumin have showed the best results by the efficiency coefficient of biological preparation use on the early stages of plant development.

Keywords: rhizohumin, azotofit, germination rate, germination.

Plants ontogenesis is taken place in close interaction with soil microorganisms that colonize the rhizosphere and form "microorganisms - root system" associations [4]. During its life activity this system is influenced by various external biotic and abiotic factors, some of which are unfavorable to living organisms. Therefore, improvement of ecosystem resistance to stressful conditions, enhancement of the organisms' protective functions with specific biological methods could significantly reduce or prevent the influence of negative factors. Thus, many authors have showed the versatile action of rhizosphere microorganisms that enter into the compositions of biological inoculants $[1,2,3,4$, $6]$.

However, the question of bacterial preparations influence on field pea seeds germination, especially during the early stages of their interaction at different temperatures remains poorly understood. Therefore, we studied the effect of biological preparations on the seedlings development in the juvenile period of plant growth at different temperature regimes.

Materials and methods. Experiments were conducted with the seeds of field pea Pisum arvense (Zvyagelska variety) used for grains and biological inoculants (Rhizohumin based on Rhizobium leguminosarum 31, Institute of Agricultural Microbiology and Agricultural Production NAAS) and Azotofit (based on Azotobacter chroococcum, "BTU Center"). The following parameters were recorded: germination rate, germination capacity, root system and seedlings growth rates depending on inoculation and temperature regimes.

Germination rates and germination capacity was determined in laboratory using standard method [5]. Field pea Pisum arvense seeds germination rates were determined after 72 hours. Root system and seedlings growth rates were measured on the $4^{\text {th }}, 5^{\text {th }}, 6^{\text {th }}$ and $7^{\text {th }}$ day. Repitability of model experiments - three-fold. Statistical processing of the experimental data was performed using standard methods $[7,8]$.

Results and discussion. Laboratory studies had established that biological preparations differently affect seeds germination rates depending on the 
temperature. Thus, the optimum temperature for germination of field pea seeds was $15{ }^{\circ} \mathrm{C}$ and $20{ }^{\circ} \mathrm{C}$. In this regime the highest seeds germination rate by the seventh day of experiment was $80-94 \%$ (depending on the treatment (Fig. 1a). The biggest number of germinated seeds $-92-94 \%$ at these temperatures was recorded in variants with Rhizohumin, with maximum $94 \%$ - at $20{ }^{\circ} \mathrm{C}$, that exceed control values on $10-15 \%$. Efficiency ratio of Rhizohumin to Azotofit for seeds germination was $1.02-1.19$ (Fig. 1b). It was established that both increase up to $24{ }^{\circ} \mathrm{C}$ and decrease of temperature to $10{ }^{\circ} \mathrm{C}$ have reduced the efficiency of biological preparations as compared to the control on $9-24 \%$.

During examination of seeds germination the germination rate index should also be considered defining the growth rate. Thus, the highest germination rate of field pea seeds was observed at $20{ }^{\circ} \mathrm{C}(50-62 \%)$ (Fig. 2a). Slightly lower germination rates were recorded at $15{ }^{\circ} \mathrm{C}$ and $24{ }^{\circ} \mathrm{C}$. Moreover, at $24{ }^{\circ} \mathrm{C}$ the germination rates of seeds treated with different microbial preparations, did not exceed control values. At $10^{\circ} \mathrm{C}$ the percentage of seed germination was $20-32 \%$, which is $1.3-1.7$ times lower when compared to the $15^{\circ} \mathrm{C}$ and $24{ }^{\circ} \mathrm{C}$ temperature regimes.

Rhizohumin have showed the advantages over the control and Azotofit by the germination rate index $(32-62 \%)$ in laboratory conditions at different temperatures except for the variant with $24{ }^{\circ} \mathrm{C}$ temperature. At this, the efficiency ratio of Rhizohumin to Azotofit for germination rate was 1.1 - 1.6.

Rhizohumin have also predominated in laboratory studies in terms of development rates of main indicators of field pea seeds germination at different temperatures (Fig. 3). Thus, seed treatment with Rhizohumin the number of germinating seeds per day was in $1.1-2.1$ times higher than in control, depending on the temperature (Fig. 3a). Efficiency ratio of Rhizohumin to Azotofit by this index was $1.1-1.6$ depending on the temperature and development rates. Correspondingly, the growth of roots of first order at Rhizohumin application was more intense than in control plants (in $1.1-1.8$ times). The efficiency ratio between the studied preparations was $1.1-1.8$, except for the variants with seeds exposed to $24{ }^{\circ} \mathrm{C}$ temperature, where Azotofit had an advantage with a efficiency ratio $1.1-2.5$ depending on the development stage in dynamics (Fig. 3b).

Inoculated seedlings have exceeded control values not only by germinating capacity and dynamics of growth processes, but also by root mass. Thus, influenced by biological preparation the raw root weight was higher on $2-22 \%$ when compared to control where the root mass was within the $0.023-0.043 \mathrm{~g} /$ plant, depending on the temperature.

Similar growth peculiarities were also observed in study of vegetative mass development in variants with Rhizohumin inoculation. Seedlings in this variant were formed $5.43-18.0 \mathrm{~mm}$ long in up to 8 units (Fig. 4). The best conditions for shoots formation were established at $20{ }^{\circ} \mathrm{C}$ with the growth dynamics $0.02-0.08$ $\mathrm{mm}$ per day. Compared to control plants in variants with Rhizohumin inoculation were developed better in $1.2-2.8$ times. At this, the efficiency ratio of Rhizohumin to Azotofit was $1.8-4.8$ except for the variant with plants grown under the $24{ }^{\circ} \mathrm{C}$ temperature. 


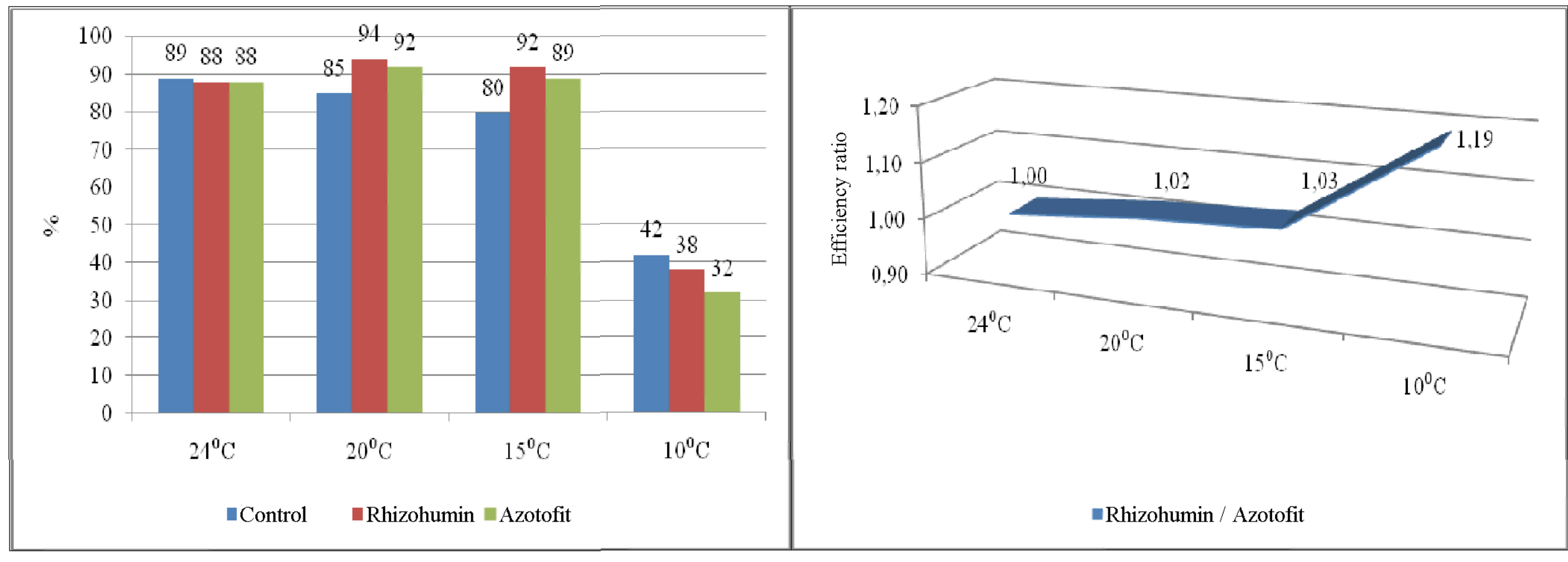

FIGURE 1. Effect of temperature on field pea Pisum arvense seeds germination on the seventh day (a) and comparative analysis of the biological inoculants impact (efficiency ratio) (b) on seeds germination based on the temperature 


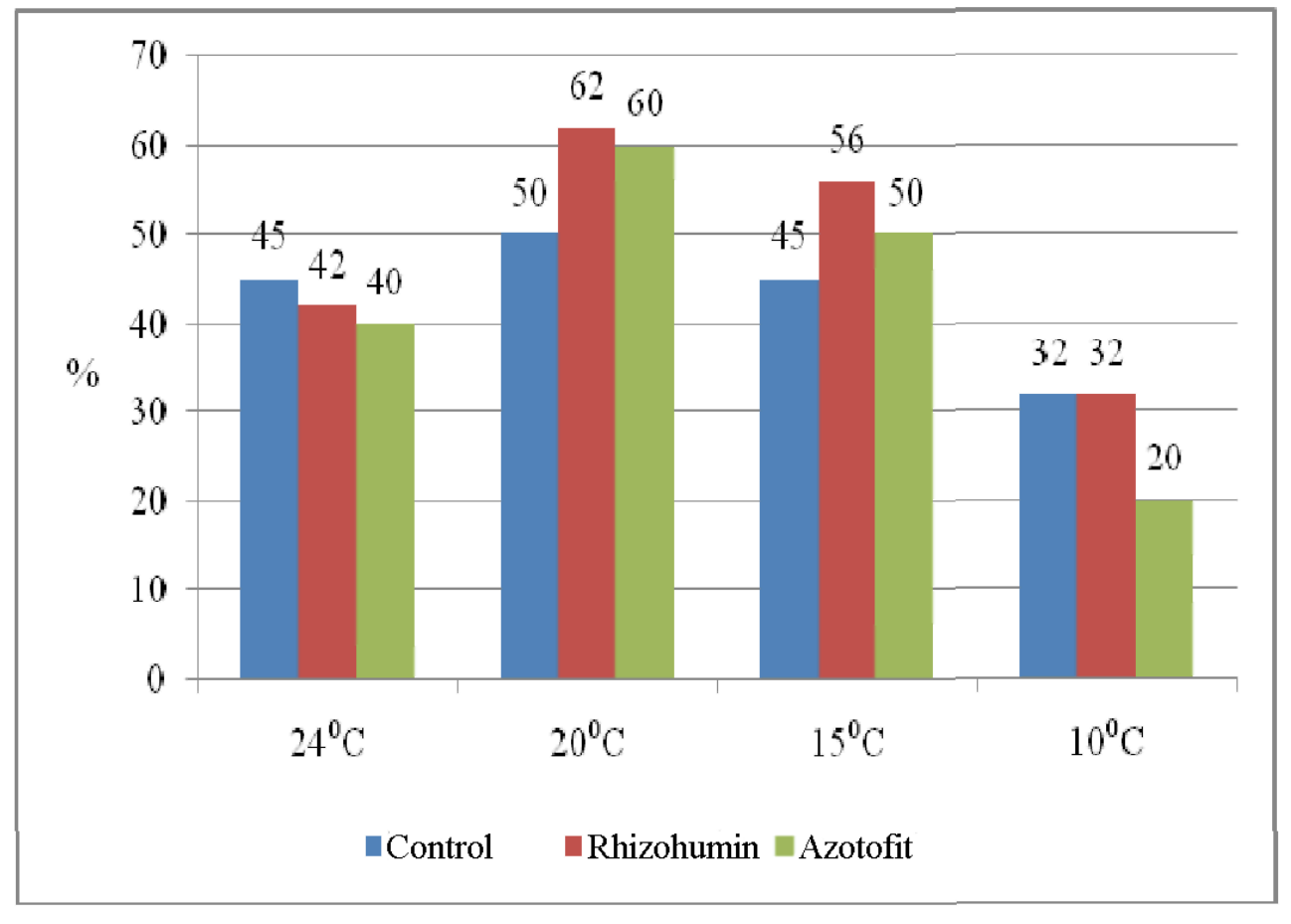

$a$

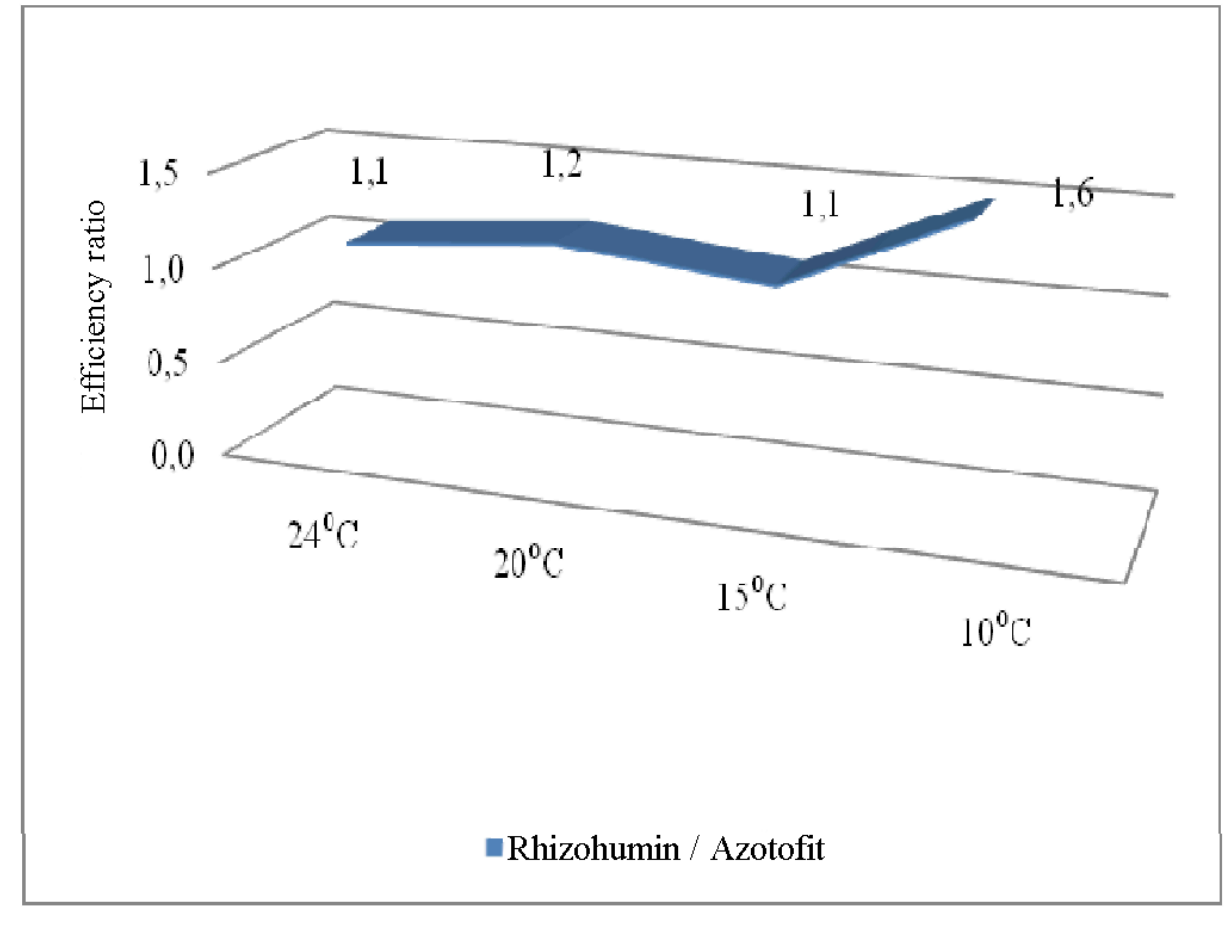

$b$

FIGURE 2. Effect of temperature on field pea Pisum arvense seeds germination rates (a) and comparative analysis of the biological inoculants influence (efficiency ratio) (b) on seeds germination rates in different temperature regimes. 


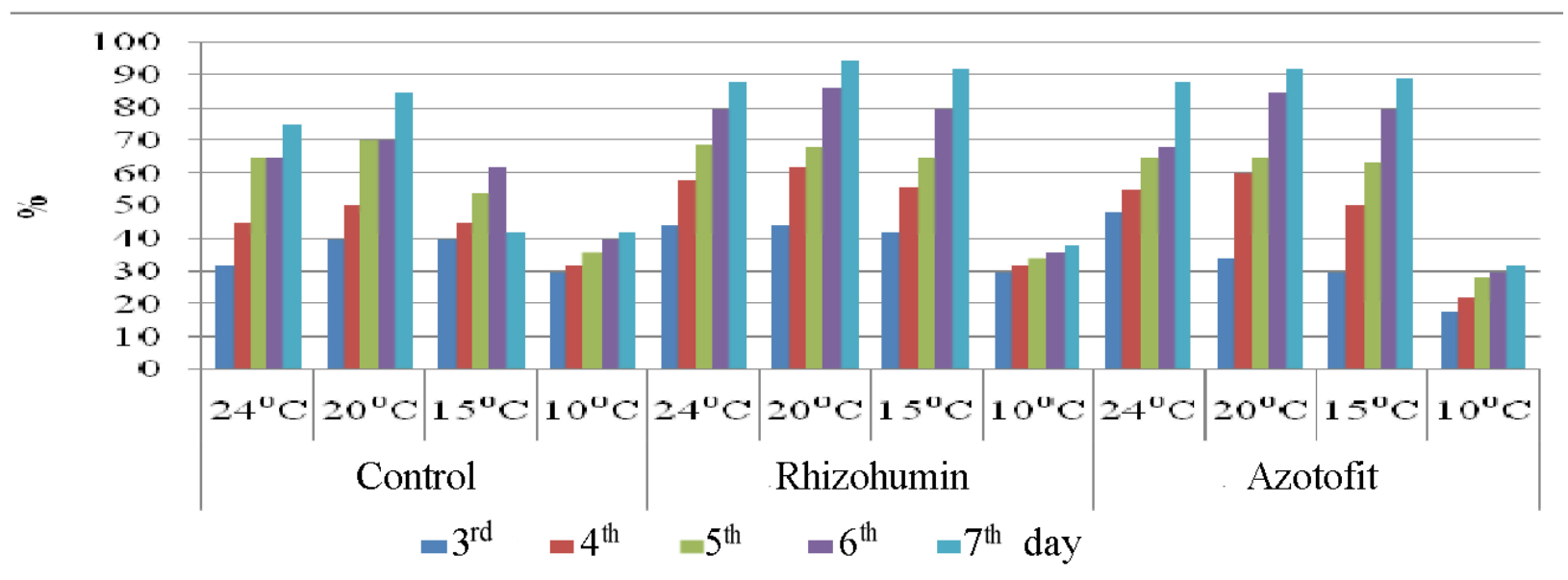

$a$

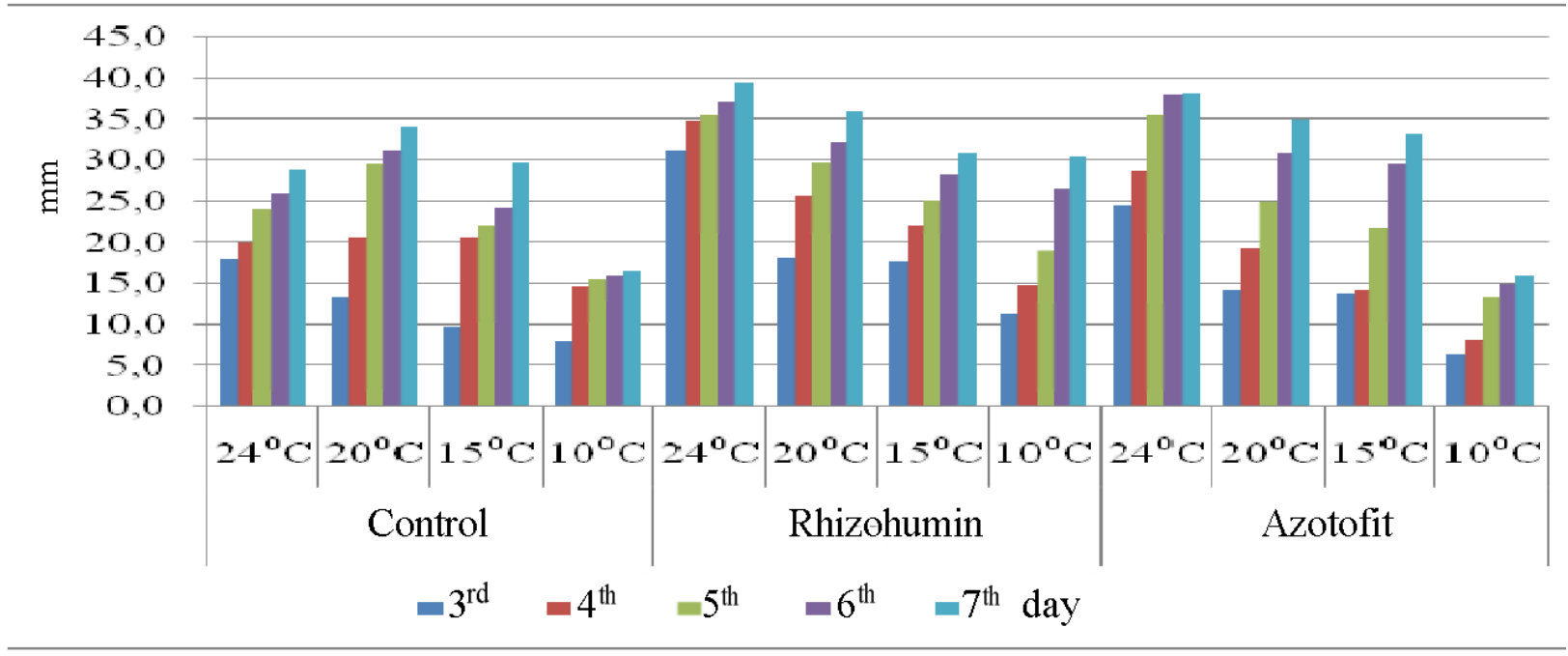

$b$

FIGURE.3. Germination and root development rates of field pea Pisum arvense, depending on the biological preparation and temperature.

Note: $a$-number of germinated seeds, $\%$; $b$ - length of the roots of the first order, $\mathrm{mm}$

Hence, it was established that biological preparations based on the rhizosphere bacteria have a positive effect on germination capacity and germination rate of field pea Pisum arvense seeds, as well as on plants growth and development in the early stages of their ontogenesis. It was shown that biological preparations perform better under the $15^{\circ} \mathrm{C}$ and $20^{\circ} \mathrm{C}$ temperature conditions with Rhizohumin predominating effect on seeds germination and seedlings growth rates. 


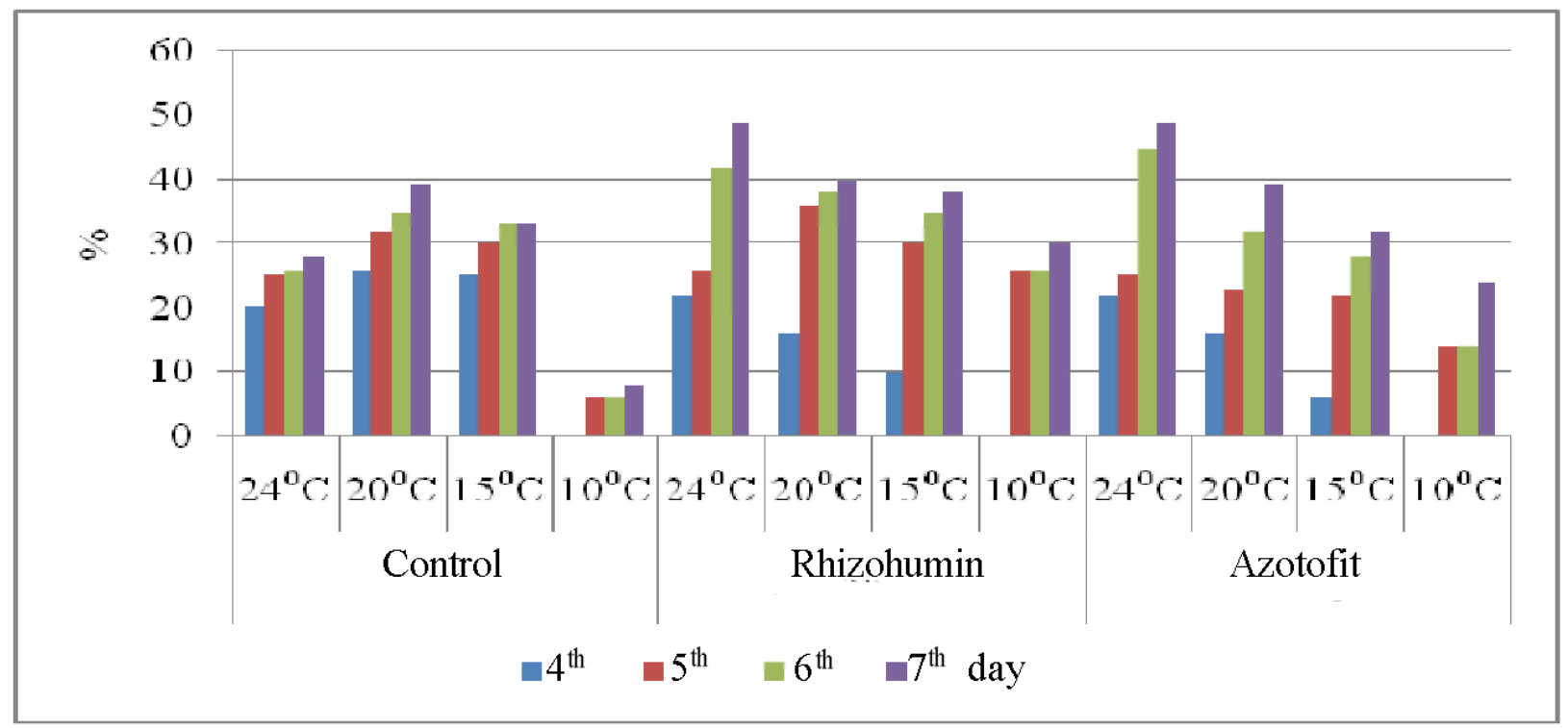

$a$

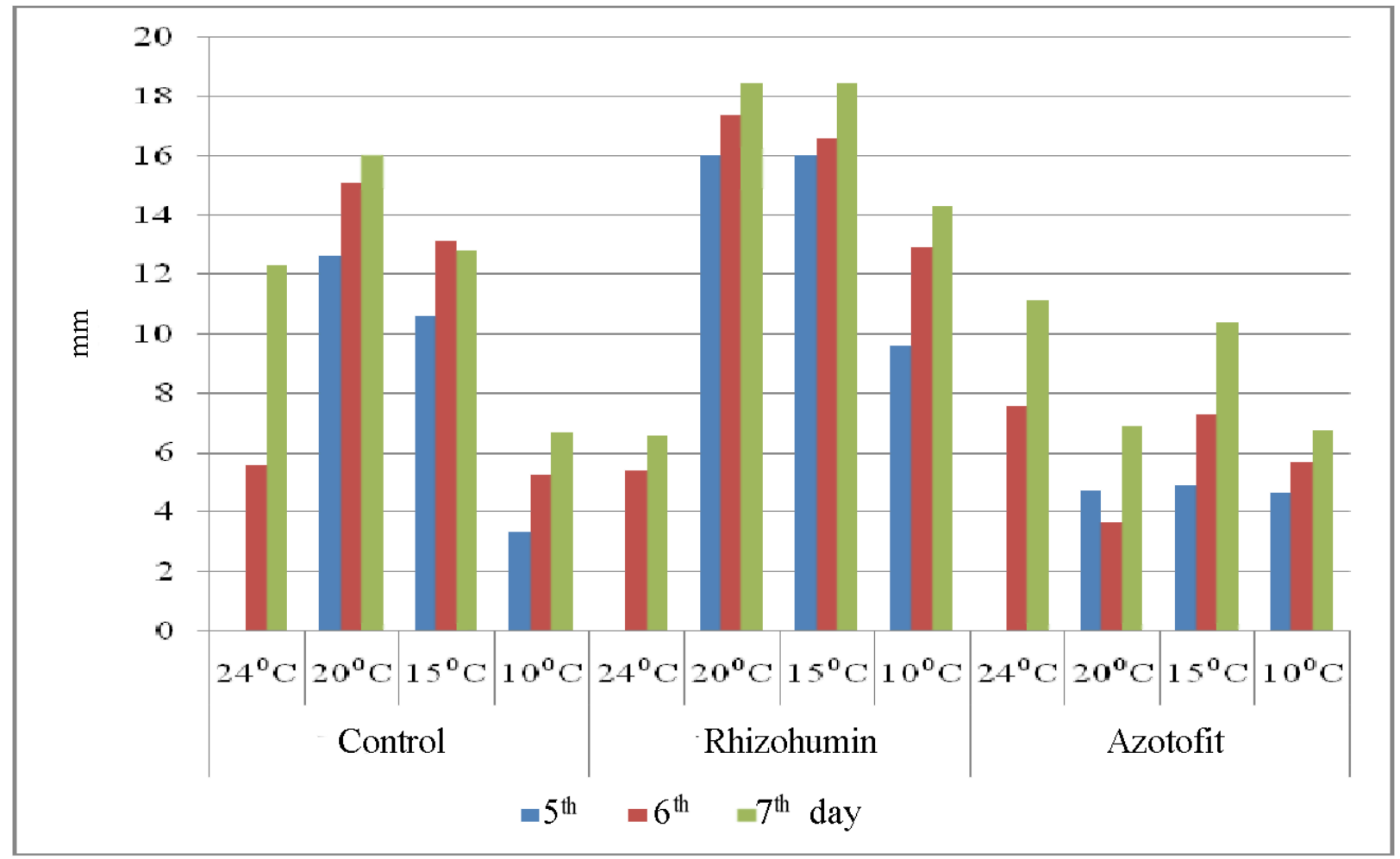

b

FIGURE 4. Vegetative mass accumulation rates of field pea Pisum arvense during seeds germination, depending on the type of biological preparation and temperature.

( $a$ - number of seeds which formed shoots, $\% ; b-$ shoots length, $\mathrm{mm}$ ) 